\title{
Forum
}

\section{Theory: A Short Guide for Classicists}

\author{
Jerome Moran
}

Key words: Critical Theory, Alterity, Essentialism, Reception, Intertextuality

'Weapons of mass deconstruction' (Anthony Kenny, TLS, 21 June 2013)

'... summary accounts of literary theory are often embarrassed before their own inadequacy.' $\left(O C D^{3}\right.$, p. 871$)$

In addition to the 'Key words' at the head of the article that are provided for online searches, there are a number of other terms that may be regarded as key words in Theory, i.e. terms that tend to recur in works of Theory, works about Theory, and works that employ Theory, terms by which the presence of Theory may be recognised. Many of these are French (or German) words that an English rendering may not fully explicate. Also, they cannot be fully understood outside the context in which they are used, which is a necessary limitation on books about Theory, necessary though these are for beginners. (Wittgenstein famously said that one should not ask for the meaning of a term but look for the use.)

Actually, the terms that the reader is likely to encounter most are the names for the different forms of Theory. I have given a long list of the most common of these in the article. No list can be complete or up-to-date as they keep on being added to, almost every day, it sometimes seems. I regularly meet new ones in book reviews, many of which will have a short shelf-life, one feels. But this was said at the time of the early and by now well-established forms of Theory, so one cannot predict the staying power of new forms.

Oxford University Press currently has a series called Classics in Theory. The editors/publishers say of the series:

Classics in Theory explores the new directions for classical scholarship opened up by critical theory [my italics]. Inherently interdisciplinary, the series creates a forum for the exchange of ideas between Classics, anthropology, modern literature, philosophy, psychoanalysis, politics, and related fields.

The following extract from a recent review (BMCR 2020.3.11) by Ben Brown of Richard Seaford's Tragedy, Ritual, and Money in Ancient Greece: Selected Essays (2018) is instructive of attitudes to

Author of correspondence: Jerome Moran, E-mail: jeromemoran@hotmail.com Cite this article: Jerome Moran (2020). Theory: A Short Guide for Classicists. The Journal of Classics Teaching 21, 80-85. https://doi.org/10.1017/S2058631020000434
Theory by Classicists (and not just Classicists) over the last half-century or more:

The reception of continental thought in Anglophone classical studies during the 1960s and 70s had few students whose work, like Seaford's, was able to overcome the reactions to theory that emerged as a kind of orthodoxy in the decades since the end of the Soviet Union. The systematic reception of contemporary French thought in classical studies took place in earnest more than half a century ago in many leading transatlantic universities, generating the momentum necessary to convince a reluctant field of the powerful contribution theoretical and critical approaches could make to the interpretation of hallowed texts. These self-reflexive and historicist approaches (largely French, especially from the so-called 'Paris School') refocused scholarly attention away from identity to radical difference by interrogating the assumption that Greek literature was produced according to universal (i.e. our) 'literary' criteria. Yet, just as quickly, after the apparent discrediting of critical theory in the post-Marxist landscape after 1991, the exponents of these critical-theoretical approaches to classical texts began falling back to intellectual ghettos, their work increasingly patronized as 'dated Parisian' or worse, greeted with triumphal incomprehension by those rushing to embrace a return to identity with the Ancients.

Read on ...

\section{Preliminaries}

Classicists have as much right - and need - to know about Theory as their colleagues in modern studies. The texts that we (teachers and students) read both in and about Greek and Latin literature have no special exemption that I know of from the pronouncements of Theory. Anything that constitutes a 'text' is available for analysis by Theory. In fact, the scope of Theory goes beyond literature and is applied to many other aspects of the cultures of ancient Greece and Rome (see, for example, the recent Theory-driven book (2018) on Athenian society by Greg Anderson, The Realness of Things Past: Ancient Greece and Ontological History). I think that all this is now generally acknowledged by Classicists (it certainly is in the USA and Continental Europe). 
This, with some alterations, is what I wrote as the opening paragraph of an earlier version of this article. It still stands and I believe it is still true. However, since it was written two years ago, I think that there is or soon will be even more need for Classicists in the UK to become familiar with Theory. The earlier version was not accepted for JCT since it was thought to be peripheral to the interests of Classicists. I don't think that the same can be said of the situation today.

Since I wrote the earlier version of the article there seems to have been a resurgence of Theory (especially Narratology, Reception Theory, Reader-Response Theory, Intertextuality, New Historicism, Cultural Materialism, Postcolonial Theory, and of course Feminism and LBGT(Q)) in the work of Classicists in the UK, to judge from publications and publishers' lists, and from reviews posted on BMCR. (If you want further evidence of the growing presence of Theory in Classics, and the growing number and variety of theories, see the BMCR review of Mario Telo, Melissa Mueller, The Materialities of Greek Tragedy: Objects and Affect in Aeschylus, Sophocles, and Euripides (2018) in BMCR 2019.11.03. Soon writing from the standpoint of an avowed variety or varieties of Theory will be obligatory.) I put this down to the increasing number of scholars, especially younger scholars, from Continental Europe and the USA (where Theory has not abated, nor an interest in it slackened) who are now working in UK Classics departments. (I have heard it said that they are here in such numbers because there are no longer enough of the home-grown variety coming through who are their equal in ability.) If this trend continues, it will not be long before students, undergraduates as well as postgraduates, will be required to have a working familiarity at least with Theory. I doubt that many Classics departments will introduce courses in it, especially for undergraduates; and there is a shortage of accessible aids for absolute beginners.

There is not space here to give an account of any of the many theories that are subsumed under the label 'Theory' (see below). For Classicists the entry 'literary theory and classical studies' by the Fowlers in $O C D^{3}, \mathrm{pp} .871-875$, provides a useful conspectus of a large part of the field, if a little dated now. Also helpful is Malcolm Heath, Interpreting Classical Texts (2002). Two of the shorter and more accessible guides to Theory generally are Jonathan Cullen, Literary Theory: A Very Short Introduction (1997) and Peter Barry, Beginning Theory (2002), the latter of which I have drawn upon in places in this article. This article provides no more than a rough and ready outline of what Theory is, and its main purpose is to 'flag up' the importance of becoming (more) acquainted with it if one is to be able to understand the increasing number of publications informed by Theory.

(Teachers of Classics, if they find this article helpful, may like to share it with colleagues who teach English, especially English Literature (especially ones who struggled to understand Theory when studying it as part of their degree course). These days they may well be teachers of English themselves, as the writer himself has been. And Classicists in their day have often been pioneers in inter-disciplinary studies, e.g. social anthropology, religion, sociology, linguistics.)

This article necessarily refers to and makes use of certain concepts and arguments drawn from Philosophy. The reader does not need a background in Philosophy in order to understand them. They are certainly no less accessible at any rate than many of the pronouncements of Theory - or guides to it (this one excepted, I hope).

\section{Materials on Theory}

There are four different types of materials to do with Theory. There is overlap of content, especially between the first and third and fourth types with regard to the application of Theory.
1. A first-order book of Theory. This sets out a particular form of Theory. Books (or articles) by well-known exponents of Theory such as Barthes, Derrida, Lacan etc. belong to this type.

2. A second-order book about a first-order book or books of Theory. This sets out to give an exegesis of the first kind of book. The books by Cullen and Barry (see above) are of this type. This is the kind of book that is most useful to beginners.

3. A book which applies a form or forms of Theory to a given subject, literary or non-literary, a book that is written from the standpoint of a form or forms of Theory. The author does not always specify the form of Theory, but it is usually possible for the reader to identify it. The books by Anderson and Telo/ Mueller (see above), and the books in the OUP Classics in Theory series fall into this category.

4. 'Readers' (books of selected writings) are available for many authors of the first kind of book, and for particular forms of Theory. These will usually contain important articles as well as extracts from books.

\section{Theory in the classroom}

By 'classroom' is meant here any teaching forum for Classics students for whom learning about Theory is considered appropriate. There is little (formal) teaching of Theory at present for Classics students, either in schools or the university. But first things first: would-be teachers of Theory must first equip themselves with the necessary competence in Theory in order to pass it on to their students. In order to achieve this, Theory must become, as it has with English studies, an accepted component of degree courses in Classical studies.

Assuming such competence then on the part of the instructor, teaching Theory as a pedagogic strategy deployed to enhance students' reception of a text or their understanding of a cultural phenomenon might proceed along the following lines (a bald outline that would need to be fleshed out in practice):

1. Ensure that the students have a good understanding of the relevant form(s) of Theory, relevant to the text or cultural phenomenon to be studied.

2. Confirm that the form(s) of Theory are appropriate to the subject matter.

3. Apply what the Theory says to the subject matter under study.

4. Ask whether the application of Theory to the subject matter suggests ways in which the subject matter can be interpreted.

5. Does the application of Theory challenge traditional and received interpretations?

6. Does the analysis of the subject matter by Theory lead to a fuller, richer, more nuanced and balanced understanding of the subject matter?

So Marxist or Postcolonial Theory might be applied to the study of empire or provincial rule, or to issues of cultural alterity. There are so many different standpoints and perspectives from which the same material may be viewed, which is one of the benefits of the application of Theory.

\section{Theory and its origins}

In what follows 'theory' (with a lower case ' $\mathrm{t}$ ') has its usual meaning. Also, preceded by 'literary' it denotes literary theory mainly before the $20^{\text {th }}$ century. 'Theory' (with an upper case ' $\mathrm{T}$ ') denotes 20 th century theory, especially works written from about 1950 onwards. This orthographical distinction is a useful one even though it 
cannot always be applied entirely consistently. So, for example, Practical Criticism is usually regarded as one of the enemies of Theory rather than as a form of it.

Theory (with a lower case ' $t$ ') is generally taken to be an idea or system of ideas that purports to explain something, and/or to form the basis for some practice or activity. Literary theory in general (it takes many particular forms: see below) purports to explain what literature is and how to read a literary text, and thereby to provide a basis for the practice of reading literary texts. (Literary criticism is the application or deployment of literary theory to the critical reading of literary texts.)

What is called 'Theory' is also known (in literary circles at any rate) as 'Literary Theory' or 'Critical Theory' (not to be confused with the use of the same expression to denote the Frankfurt School), or 'Continental Theory' (because largely non-Anglophone) or 'French Theory' (because most of the original and seminal texts are in French). I shall call any and all manifestations of it simply 'Theory'.

Literary theory predates Theory. The earliest works belong to the fifth and fourth centuries BCE, if not earlier, and were written by the ancient Greeks. Some of the ideas of Theory can be glimpsed in English works of literary theory by the Romantics, e.g. Shelley and Coleridge, and by Victorian writers and critics. And Theory is influenced by ideas in Philosophy going back centuries (see below). Theory is not as radical or revolutionary as it and its supporters often claim, nor is it as alien to Anglophone theory as it is thought to be, though certainly the style in which much of it is written is different from the conventional academic English that one has been used to ('has been' rather than 'is': it is encroaching increasingly on academic English).

As stated earlier, Theory is essentially a $20^{\text {th }}$ century phenomenon. Its heyday, in its Continental forms at any rate, was the 1960s to the 1980s; but its origins can be traced back to the late $19^{\text {th }} /$ early $20^{\text {th }}$ century. (As already mentioned, some of its ideas go back much further than that and are shared with, if not taken from, Philosophy going back centuries.) Theory (especially Continental Theory from about 1950 onwards) was not a movement that developed within literary studies itself in the first instance. Rather, it originated outside literary studies within other disciplines (especially Linguistics and Social Anthropology) and the intellectual Zeitgeist generally, and it was imported into literary studies because its ideas were thought to be applicable to the study of literature, especially as they were seen as presenting a radical challenge to the prevailing (mainly Anglophone) orthodoxy of Liberal Humanism. Liberal Humanism was concerned mainly with the biography, personality and (most importantly) intentions of the author, and, generally speaking, with matters extraneous to the text itself that were nonetheless considered relevant to a 'correct' response to and understanding of the text. Theory in its various ways rejected all of these concerns. Instead of focusing attention on the author as the determinant of the 'meaning' of a text, it first focused on the text itself, then on the reader of the text.

Theory generally no longer has the following it used to have, certainly in Anglophone countries. It is no longer generally assumed as a matter of course that one cannot engage seriously in literary studies except from the standpoint of Theory, or from a particular form of it. (But I no longer feel so confident that either of these assertions is true.) However, it still informs a good deal of writing about literature, including Classical literature, especially in academic circles, even in Anglophone countries, if the USA is anything to go by. Also, many of its ideas have been accepted by those who do not endorse Theory wholeheartedly as the only viable approach to serious literary study. And many of its criticisms of how literature used to be taught and studied are justified. For these reasons every serious student or teacher of literature, including Classical literature, needs to be aware of what it has to say for and about itself, and of the criticisms of and objections to Theory.

'Theory' is in fact the name for a collection of different, though often related, theories, or forms/branches of, or approaches to, Theory. There are more than 20 of these (see my 'Conspectus Of Theory' below), many of them constituting a series of 'chronological waves', and based on about half-a- dozen or so ideas, not all of which are genuinely new, since they have their origins in ideas, usually in Philosophy (whether Theorists are aware of it or not), that pre-exist Theory, in some cases by many centuries (chiefly, philosophical idealism, nominalism, existentialism, scepticism and relativism).

Most of these forms of Theory are in their different ways reactions against 'Liberal Humanism' (as well as reactions against each other). 'Liberal Humanism', as used by Theorists, is a term of abuse, especially in the 1970s, for literary studies before the advent of Theory. It is regarded by Theory not as a rival theory, or set of theories, but rather the absence of theory, and therefore systematically defective as a tool for interpreting literature. 'Liberal' is used to mean the absence of commitment, especially to any (or a particular set of) socio-political ideas. 'Humanism' here refers to the tradition of literary studies that has its origins in the Humanists of the $12^{\text {th }}$ century, or earlier, and to certain essentialist beliefs about 'human nature', and an assumption of the primacy of focus of the human being, as given constants in literature (see below).

Theory, or rather the manner in which it is expounded in the primary sources, presents additional difficulties to people who are not at home with languages other than English, specifically French and German, especially the former. This is because most of the primary sources are written in French, especially the most seminal and influential of them. Nearly all have been translated into English. But where the translations are faithful, they often preserve the faults of the originals as far as clarity and ease of understanding are concerned. 'Rhetorical' would be a kind way to describe the style of many of the originals; and rhetoric is not always conducive to clarity. Some of the writings seem to be tricksy parodies (deliberately?) of the kinds of convoluted readings of the texts that they propose, which is not exactly helpful to the reader new to Theory. Generally speaking, one will struggle to understand the primary sources without the aid of a guide in the form of a book in English about Theory.

One could give countless examples of the exotic and seemingly inscrutable language used by Theorists. But to do so would be unfair to Theory, for they would lack a context and the wider context within which they may well be meaningful, even true. After all, the same might be said of the propositions of metaphysics or of Continental philosophy in some of its forms.

\section{Theory and 'the meaning of a text'}

Theory (with an upper case ' $\mathrm{T}$ ') is concerned above all with meaning, specifically with the meaning of a text and how its meaning is generated (by the author? by the text itself? by the reader (original or subsequent)?). It seems, however, to be more concerned with how meaning is and is not created and less with what meaning is. (It is also concerned with the meaning of 'text' and what a text is, but that is a different, though not unrelated, matter.)

Theory is also prepared to say other sorts of things about meaning, e.g. that is not single, absolute, fixed, correct etc. But what is it exactly that is not any of these things? 
Do we in fact know what meaning is - meaning in the sense of signification, i.e. the meaning of a linguistic item of some sort, rather than meaning as significance/value/importance, e.g. 'My life has no meaning', or meaning as intention, e.g. 'She didn't mean to do it'? Philosophers of language at least are by no means agreed. If we do not know what meaning in this sense is (and it is surely meaning in this sense that Theorists are concerned with), are we in a position to say that it is or is not one thing rather than another? Is Theory based on an assumption that we do know what meaning is, and that therefore we can say that it is: something that does or does not inhere objectively in a text; is/is not created by the fiat of an author; made by the reader ('recipient') of a text; is discovered by a reader; is determined by the words used by the author or the mens auctoris; is determined by the original readers of the text who, for various reasons, were alone capable of descrying its meaning?; is something that exists only insofar as it is 'realised' by a present reader of the text?

Can we even talk meaningfully of the meaning (singular, note) of a text? Is a text, taken as a whole, something that can be said to have $a$ meaning? If so, in what sense of 'meaning'? Certain kinds of utterances, and their constituent terms, spoken or written, have 'meaning. In what sense can a text be said to have a meaning, other than and separately from the meanings of the utterances it contains? Or does a text have a meaning in a different way from the way that other linguistic items have meaning? What might this be? Is the meaning of a text a function of the totality of the meanings of the utterances and their constituents that it contains? What could this mean?

According to some exponents of Theory, notably Derrida, the meaning of 'meaning' can be no more fixed than the meaning of any other term. If this is the case, how is it possible to say anything meaningful, let alone true, of meaning and the meaning of a text?

Or should Theory itself be regarded as a series of contributions to the attempt to define what 'meaning' is, especially when used of a text? Are exponents of Theory engaged in the same kind of enterprise as philosophers of language?

I would say that the meaning of a text (if it is allowable to talk of the meaning of a text at all) is the totality of its effects upon the reader, whenever and wherever, cognitive, affective and aesthetic, however such effects are produced, but always through a combination, in varying proportions perhaps, of author, text and reader. It follows that, unless the total effects upon every reader at any time are identical, the same text can never have a single meaning. Whether any of these multitudinous meanings are more 'privileged' than others, whether there is a single 'correct' meaning discoverable by an assiduous and perspicacious reader, are different questions. Theory in general is inclined to say 'no' to both of these questions.

But why should the same text have different effects upon different readers? (I am assuming that the text itself, as opposed to the meaning of the text, is not something constructed by the reader, partly or wholly, so that one can talk of the 'same' text. This assumption would be contested by some Theorists.)

\section{The main ideas of Theory}

The theories that make up Theory have certain ideas in common. The main ones are these:

1. There is no such person as a 'naive reader', i.e. a reader devoid of any mental content, content that they bring to the reading of a text and which shapes, even determines, their reaction to and interpretation of a text. This is the case whether the reader is aware of it or not - in fact the reader is usually not aware of it, since the mental content often consists of unconscious/unexamined assumptions and presuppositions. Many Theorists would say that every reader brings some theory to the act of reading, even if it is not one of those that constitute Theory. What Theory does is to formalise, organise, focus and make explicit what the reader brings to the reading of the text.

2. There are no such things as 'essences', especially the unchanging, universal 'human nature' beloved of Liberal Humanism that literature foregrounds. The belief that things - and people, for whom 'human nature' is thought of as an essence have essences is the belief that they have an identical, fixed property, or nexus of properties, which is essential to their existing and to their being the (type of) things they are, and which they cannot lose without ceasing to exist or ceasing to be the (type of) things they are. Essences are thought of as the necessary properties of things, as opposed to the merely contingent or accidental properties, properties they simply happen to have and may not have without ceasing to exist or being the (type of) things they are. (This is an attack on 'Essentialism' and seems to have much in common with a central theme of Existentialism.)

3. Texts have no single 'meaning', or any fixed 'meanings', or any pre-existing 'meanings' (imposed by the author and existing as an inherent property of the text prior to and independently of the reader). ${ }^{1}$

4. Truth claims are always contingent and provisional and able to be revised and overturned. ${ }^{1}$

5. Literary judgements are always subjective and relative, never objective and absolute.

6. 'Meaning' depends (more) on the reader than the author or any inherent properties of the text. It is 'realised' by the reader rather than discovered. A text may have as many 'meanings' as there are readers of it. None of these 'meanings' is 'privileged' and there is no such thing as a 'correct' reading of a text (many practitioners of Theory seem to overlook this last point). ${ }^{1}$

7. The text is a self-sufficient entity and is all that matters; everything else, especially the author (the author is 'absent' or 'dead'), is irrelevant to an understanding of it. ${ }^{2}$

8. Language does not represent/record 'reality', it 'constructs', even constitutes, it. There is no (demonstrable) connection or relationship between language (or thought) and 'reality'. If there are both things and thoughts/verbal accounts of things, we cannot know that there are. All that we can know of is language and thought, not their supposed objects 'out there'. Any connections or relationships are internal to these rather than external to some supposed objective (i.e. existing independently of language and thought) 'reality'. Language and thought cannot be used as means of accessing 'things as they really are'. What we call 'reality' is really our thoughts about it and our verbal accounts of it. So, language and thought are the whole of reality for us. (This is an attack on 'Foundationalism.') ${ }^{3}$

(For what it's worth, I agree with points 1-5. I incline to point 6, but do not wholly agree. I reject points 7-8.)

\section{Conspectus of Theory}

What follows is a list, with dates (approximate in many cases), of the main theories/movements/schools that make up Theory, arranged in chronological order where possible and/or in groups with common or related ideas. The general trend of focus is from 
author to text to reader. You can find out about the main exponents of each from any competent and reasonably comprehensive book on Theory or literary criticism. The theories most associated with Theory are 3 and 7-9 (though these are no longer the ones most encountered these days, except perhaps for Structuralism). The whole thing got started really when 7 picked up certain ideas from 3 and began to run with them. This is when the 'paradigm shift' in literary studies got under way. Sometimes Theory is identified in popular thought with French Theory alone, sometimes exclusively with 7-9. In general, one may say that the history of Theory may be divided into those theories that are based on the work of Saussure and those that are more or less independent of Saussure and plough a different furrow, as it were.

1. Liberal Humanism (pre-1900) $]^{4}$

2. Hermeneutics (pre- and post-1900)

3. Semiotics \& Semiology: Saussure (Course In General Linguistics, (1916))

4. (Russian) Formalism (1915-1930 and beyond) \& Dialogism

5. Practical Criticism (1920s-)

6. New Criticism (1935-1960)

7. Structuralism (1950-)

8. Post-structuralism and Deconstructionism (1960s-)

9. Post-modernism (1980s-)

10. Narratology (1970s)

11. Critical Theory (Frankfurt School) (1920s-)

12. Marxism (1930s \& 1960s)

13. New Historicism (1980-)

14. Cultural Materialism (1980s)

15. Psychoanalysis (1930s \& 1960s)

16. Feminism (1970-)

17. Reception Theory (1960-)

18. Reader-Response Theory (1970-)

19. Postcolonial (1990-)

20. $\operatorname{LBTG}(\mathrm{Q})(1990-)$

21. Ecocriticism (1990-)

19-21 are known as 'special interest' theories.

More recently, newer forms of Theory have emerged:

Presentism

New Aestheticism

Cognitive Poetics

Transversal Poetics

Historical Formalism

No doubt there are others too.

\section{Objections to Theory}

See also the comments made in the section on the main ideas of Theory and in the Notes below.

1. Theory is unreasonably dismissive of Liberal Humanism, e.g. in not acknowledging the importance it places on the educational, cultural and moral dimensions of literature, if often from a blinkered standpoint. And the dismissal does not sit well logically with Theory's avowed openness to all interpretive strategies for reading texts.
2. The difficulty of applying in a practical way many of the theories to the actual reading of texts (see further comments on this below), as is shown by the unconvincing attempts to do so by the exponents of Theory themselves. Theory is just that, and does not, as some theories do, provide a sound basis for practice.

3. Much of the technical terminology devised by Theory is more of a hindrance to understanding than a help. The novelty of terminology seems intended to draw attention to the avowed novelty of the concepts it denotes.

4. As already noted, the manner and style in which much of Theory is written makes it difficult to understand. Why can't it be expressed in plain English? Much of this is deliberate, of course, to mirror self-referentially the perceived complexity and ambiguity of the texts themselves. One is supposed to approach the exposition of Theory itself in the same way that one approaches the texts - it is itself a text, after all. This is all well and good, but the effect is too often daunting and frustrating if what one seeks is information and elucidation.

5. As already said, a lot of Theory tends to be highly rhetorical in style. In fact, a lot of literary Theory is highly literary, with an excess perhaps of figurative language, especially the use of metaphor. A more literal use of language would be a help to understanding. But Theory would say that 'literal' suggests that language is univocal rather than systematically equivocal.

6. In much of the exposition of Continental Theory, as in continental philosophy, there is an absence of the kind of painstaking analysis and argument one is used to in Anglophone philosophy and academic writing generally, and instead of it an abundance of often cavalier assertion, often with a rhetorical flourish.

7. In spite of the element of jouissance in writers such as Barthes, Lacan et. al., there is little mention of the enjoyment to be had from literature (as, for example in Sidney's Apology For Poetry, arguably the earliest work on literary theory in English), nor of the other valuable humanising functions, affective and aesthetic, literature performs for the reader, e.g. consolation, empathy, heightening of sensitivity and augmenting of sensibility. No doubt such things bear the unacceptable stamp of the ingenuousness of Liberal Humanism. ${ }^{5}$

8. A lot of Theory, in spite of its avowed openness to alternative interpretive approaches, tends to be exclusive and partisan. Adherence to a particular theory or set of theories can become a straightjacket that prevents one from being open to other insights and interpretations.

9. The misunderstanding and misapplication of terms, concepts, arguments and theories borrowed from philosophy, e.g. meaning, truth, necessity, reality, identity.

10. The solipsistic strain in Theory and the denial of inter-subjectivity: my own subjective experience is all I can know to exist. Language and thought constitute the only 'reality'. But language presupposes a user, perhaps a community of users.

11. The subversive, free-for-all, ludic nature of some Theory, especially Post-modernism, tends to have the effect of undermining one's view of literature and literary studies - and not just literature - as things to be taken seriously.

12. Related to 11 is Theory's view that all literary texts are of equal worth and value, so far as literary merit is concerned; or that a literary text has no more claim on our attention than any other kind of text. This may lead one to suppose that there is nothing worthwhile to be gained from literature.

13. Of the many on offer, how does one know which theoretical standpoint(s) to adopt and deploy for a given text? Always the 
same one(s)? Pick and mix? Hit and miss? Try on for size? Trial and error? Different ones for different parts or aspects of the same text? Does it depend on what sort of text it is? Does the nature of the text itself indicate unerringly the appropriate standpoint? But don't you need Theory in the first place to inform you of the nature of the text? These problems are not faults in Theory itself, of course; it is more of a methodological difficulty posed by the plethora of possible methods of tackling a text.

14. Theory, or rather the application of Theory to texts, is really an exercise that only a professional critic can competently and confidently employ. It is not something to be practised by the inexperienced amateur and ordinary reader, even supposing that such a person knew how to go about it in the first place. It is an activity for literary cryptographers, deciphering texts for the benefit of fellow code breakers. It is not the democratic enterprise it sometimes represents itself to be.

\section{Notes}

1 Extreme statements made by Theory about the simultaneous indeterminacy of all meaning and the provisional nature of all truth claims (or the impossibility of establishing truth at all), besides being contradictory, can be applied to the statements themselves, causing them to be, per impossibile, if true, impossible to understand and impossible to verify (conclusively). If they have no determinable meaning, or even contradictory meanings, it is difficult to see how they can be true. And if they are not true then what they say about meaning and truth is false. In these respects, Theory is open to the same objections as are universal scepticism and relativism.

2 If it is true that all that one needs and that all that one should use is the text and nothing beyond the text, Classicists should be in a better position than most to interpret texts. In many instances all that we have is the text. Where extraneous information exists, especially about the author, it is usually pseudo-biographical information, often composed centuries later and concocted to fill an otherwise abhorred vacuum, so that it can be disregarded in any case. Homer is a case in point. And with regard to Homer, presumably, unless the text itself provides us with all the necessary evidence for it, we should not apply our knowledge of oral poetry and comparative literature - or of Bronze Age and Dark Age history - to our interpretation of the text.

3 Why does Theory privilege language and thought? Why should we regard these as any more 'real' than all the other things that we ordinarily take to be real? Is it because we appear to have direct access to thought (and to language insofar as thought entails language), whereas our access to other things is indirect and by means of thought (interpreted loosely as awareness on the part of the mind)? I cannot (logically) think that $I$ am not thinking, and therefore using language, if thinking is language-dependent. But whether I am doing either is a matter of fact. No facts, including psychological facts, are necessary, all are contingent. It is therefore conceivable (though not by me), i.e. it entails no contradiction, that I am not thinking or using language. So, if thinking and language constitute the only reality, it is possible that nothing is real. But of course if I think this then it must be false, since I, or my thinking, or my thought, must be real, or at least exist, if one is to draw a distinction between being real and existing (i.e. if 'real' is to be defined as existing objectively, so that things and facts are real but subjective experiences and their objects are not).

4 Liberal Humanism has been included in the list even though it is not part of Theory, but rather the common enemy of Theory. In any case, I do not see why it should not count as a theory, even if not part of Theory.

5 For some 'classic' titles on the enjoyment of reading and jouissance as a concept of Theory, see the following selection:

Philip Sidney An Apology for Poetry (c. 1580)

Roland Barthes, The Pleasure of the Text. Hill \& Wang, New York (1975), English edition of Le Plaisir du Texte (1973)

Jacques Lacan,The Seminar, Book Vll. The Ethics of Psychoanalysis (1959-1960); The Seminar, Book XVII, The Other Side of Psychoanalysis (1969-1970); The Seminar, Book XX. Encore (1972-1973), all English editions and translations published by Norton \& Co., New York.

There are also writings on juissance by Hélène Cixous and Julia Kristeva from the standpoint of Feminist Theory, influenced by and in response to Barthes and Lacan. 